\section{Armonías literarias: la música en algunos cuentos de Daniel Moyano}

Cecilia Corona Martínez
Profesora Titular de Literatura Argentina I, Facultad de Filosofía y Humanidades, Universidad Nacional de Córdoba. Directora del Equipo de Investigación "Heterodoxias y sincretismos en la literatura argentina". Directora de las publicaciones: Heterodoxias y sincretismos en la literatura argentina (2011) y Mapas de la heterodoxia en la literatura argentina (2013).

Contacto: ceciliacoronamartinez@ hotmail.com 
PALABRAS CLAVE

Literatura; música;

narrativa; Daniel Moyano

\section{KEYWORDS}

Literature; music

narrative; Daniel Moyano

\section{RESUMEN}

Daniel Moyano, escritor argentino nacido en Buenos Aires y muerto en Madrid en 1992, publicó poemas, cuentos y novelas que aún no han recibido la atención que merecen por parte de la crítica especializada. Además, fue músico profesional. Estas dos vocaciones se conjugan en una característica que destaca una gran parte de su narrativa: la confluencia entre música y literatura. Este artículo estudia la presencia de la música en un corpus de tres cuentos de Daniel Moyano, publicados entre 1974 y 1988 . Se advierte en ellos una presencia cada vez más relevante de lo musical, tanto a nivel de la escritura como en los diversos sentidos que adquiere en las historias narradas.

\section{ABSTRACT}

Daniel Moyano, an argentine writer born in Buenos Aires and died in Madrid in 1992, published poems, short stories and novels, which have not yet received the attention they deserve from specialized critics. He was also a professional musician. These two talents lead together to a remarkable characteristic of his narrative: the relation between music and literature. This paper examines the presence of music in a corpus of three stories by Daniel Moyano, published between 1974 and 1988. We notice an increasingly relevant presence of musical aspects, both in a writing level and in different senses that music acquires in narrative plots. 
Daniel Moyano, escritor nacido en Buenos Aires en 1930 y muerto en Madrid en 1992, empezó a publicar en 1960, alternadamente cuentos y novelas. Su producción narrativa no ha sido aún suficientemente destacada del conjunto de la narrativa argentina de los últimos cincuenta años.

Si bien su nombre no es desconocido para la crítica especializada; los estudios académicos sobre su obra son escasos y poco difundidos ${ }^{1}$.

Profundizando en las razones de este olvido, encontramos como primera respuesta la irrupción de la larga noche de la dictadura cívico-militar que asoló al país entre los años 1976 y 1983. Efectivamente, Moyano fue uno de los tantos intelectuales y artistas que debieron abandonar el país para arrojarse a un duro exilio, que alteró su vida entera y por ende, su carrera de escritor.

Numerosas entrevistas gráficas y audiovisuales hacen conocer detalles de su biografía, desde el nacimiento el 6 de octubre de 1930, un mes después de que el General Félix Uriburu derrocara al presidente constitucional Hipólito Yrigoyen, interrumpiendo así su segundo mandato y marcando el comienzo de una serie de golpes de estado que caracterizan la historia política de Argentina en el siglo XX.

Los hilos que manejan la vida de los pueblos enredaron también su destino. Nieto de inmigrantes italianos, su madre nacida en Brasil se casó con su padre, descendiente de criollos y aborígenes; quien la asesinó cuando Daniel y su hermana eran pequeños. Vivió entonces con sus abuelos y con diversos tíos, en ciudades de la provincia de Buenos Aires, en Alta Gracia, Valle Hermoso y La Falda (en las serranías cordobesas) y luego en Córdoba capital, que fue su ciudad hasta que descubrió La Rioja, donde se 
arraigó hasta que los vientos de la historia lo enviaron al exilio junto con su familia.

En Córdoba se manifestaron sus dos vocaciones: la música y la literatura; pasiones que alcanzó a desarrollar en plenitud en su larga estadía en la capital riojana.

En Madrid, donde se instaló en 1976, no era conocido como escritor, y así como en su primera juventud desempeñó diversos oficios, particularmente el de albañil; en la capital española trabajó en una fábrica de maquetas. Lentamente, fue adquiriendo cierto reconocimiento en España y en otros países de Europa; hasta que el cáncer lo llevó a los sesenta y dos años, en la misma ciudad que lo acogió como pobre exiliado político.

La labor literaria de Daniel Moyano fue múltiple: poesía, periodismo, cuento, novela; todos estos géneros fueron frecuentados por el autor. Su obra empezó a conocerse en Córdoba, donde publicó el primer libro de relatos: Artista de variedades, en 1960. Posteriormente, en 1966 editó su primera novela, Una luz muy lejana; en 1967 obtuvo el premio "Primera Plana-Sudamericana" por la segunda, El oscuro. En Argentina publicó también El trino del diablo [1974] y varios libros de cuentos.

Cuando fue apresado en 1976, Moyano había terminado El vuelo del tigre y la enterró en el patio de su casa de La Rioja para evitar su destrucción; pasado el tiempo no logró recuperar ese original. Tal como lo relata él mismo, la reescribió por completo en España, donde se publicó en 1981. En ese país se editaron Libro de navios y borrascas [1983], una reediciónreescritura de El trino del diablo [1988] y Tres golpes de timbal [1989]. En 1985 obtuvo el premio "Juan Rulfo", al mejor cuento en lengua española, por "Relato del halcón verde y la flauta maravillosa". De manera póstuma, salieron a la luz un libro de relatos: Un silencio de corchea [1999], una novela que no alcanzó a revisar: Dónde estás con tus ojos celestes [2005] y las nouvelles Un sudaca en la corte [2012] y En la atmósfera [2012].

Su producción, alejada del regionalismo localista, se sustenta en el plan- 
teo original de temas recurrentes de la literatura nacional desde las décadas del ' 60 y del ' 70 , tales como el autoritarismo, el exilio, el desarraigo; pero también -especialmente- en el particular modo de presencia de lo musical en las obras.

En las novelas de Daniel Moyano y en una parte de sus cuentos, la música se convierte en centro significativo, desde donde se irradian múltiples imbricaciones con lo literario. Su presencia singulariza los textos, los destaca y los diferencia, otorgándoles cualidades únicas.

Daniel Moyano realiza dos elecciones fundamentales en su producción narrativa; la primera, una renovación expresiva fundada en lo musical; la segunda, una toma de posición concreta, referida a su participación como escritor en el campo histórico-cultural de la época.

Gran parte de los cuentos y novelas de Daniel Moyano abundan en alusiones superficiales, recurrencias en el tema, en la caracterización de muchos de los personajes como músicos, todos ellos elementos desveladores de un trasfondo que recorre diversos niveles compositivos de las obras, y que se instituye como uno de los factores generadores de las mismas

Además de los personajes e instrumentos músicos, destacamos una especial concepción espacio-temporal que opone un tiempo externo (la realidad de los personajes) a un tiempo musical, interno. $\mathrm{Al}$ respecto, Claude Lévi-Strauss señala que la obra musical crea un fragmento de eternidad $(1968,25)$, aseveración que reafirma las dimensiones particulares del tiempo de la música.

Música y palabras aparecen en las novelas como hebras entrecruzadas en el entramado textual. La escritura se desliza progresivamente hacia el discurso musical, instituido como paradigma.

Como continuidad de nuestro estudio sobre las relaciones entre literatura y música, presentes en la narrativa moyaniana, hemos seleccionado un grupo de cuentos donde aparece esta constante en la escritura de Moyano: lo musical como elemento estructurador del propio discurso, a la vez que recurso alegórico-simbólico de vastas proyecciones. 


\section{CANTATA PARA LOS HIJOS DE GRACIMIANO}

Este relato está incluido en el libro El estuche del cocodrilo, de 1974. Desde el título - cantata - se alude a "una obra cantada, en varias partes, con acompañamiento instrumental de igual jerarquía e importancia artística" (Stephan, 1964,68).

La disposición gráfica del relato, separado por blancos, señala las partes de la cantata. Cada una de estas secciones marca la presencia de distintas voces: el narrador en tercera persona presenta la situación del día en que Gracimiano y Gracimiana, padres de nueve hijos, los abandonan en distintas casas para finalmente separarse; una voz en primera persona -la del comisario- cuenta brevemente la vida de Gracimiano; y otra voz, también en primera persona -la de la maestra del pueblo- habla de Gracimiana.

La decisión de destruir a su familia, es tomada por la pareja a causa del hambre. Su realidad es que ya no pueden alimentar a sus hijos y menos alimentarse a sí mismos, puesto que el padre no consigue trabajo como hachero.

Este cuento puede considerarse una suerte de bisagra donde se confunden dos ejes vertebradores importantes en la obra moyaniana: la preocupación social que se halla en numerosos relatos (entre ellos "La lombriz", "Los mil días") y la presencia de lo musical que constituye el soporte de gran parte de su obra posterior.

Ahora bien, las necesidades materiales, la situación miserable en que viven algunos protagonistas de los primeros relatos de Moyano, se exacerban en este texto despojado de toda perspectiva compasiva; donde los hechos se relatan desde una distancia que pone en primer término la insatisfacción de una necesidad básica para todo ser vivo. No se atribuyen culpas ni se estudian causas: el despojamiento de explicaciones es el correlato del despojamiento de dos seres que solo pueden perderlo todo: la familia, el amor, para intentar la supervivencia. 
En el desarrollo de la historia, la música proviene de la radio, y su función es más bien la de ayudar al olvido y a soportar la separación final: "la música siguió todavía resonando en ellos [...] sustituyó los pensamientos y todo lo demás." (Moyano, 1981,77).

Esta función menor, si comparamos este texto con otros posteriores, se apoya también en cuestiones fónicas, donde las palabras se equiparan a sonidos, carentes de significado: "un simple problema de combinar palabras, que para ellos, más que significados, serían simplemente sonidos.” (1981, 72). La equiparación sonido-palabra permite que esta última se convierta en menos dolorosa, a partir de una división entre significante / significado que prioriza el primero para no detenerse en el sufrimiento provocado por la situación que atraviesan los protagonistas.

"Cantata para los hijos de Gracimiano", a pesar de que presenta una organización discursiva fundada en la estructura de una cantata musical; no incluye a la música de manera determinante en el desarrollo de la historia. Muy diferente es su función en los cuentos restantes.

\section{EL HALCÓN VERDE Y LA FLAUTA MARAVILLOSA}

Con este cuento, publicado en 1988, el autor ganó el Premio Juan Rulfo (1985). Su lectura permite adentrarnos en ciertas constantes de la narrativa moyaniana, particularmente las relacionadas con el periodo de la última dictadura militar. Se trata de narraciones con una fuerte referencialidad, y a la vez muy alejadas del realismo tradicional; en ellas, la violencia no se muestra directamente, sino alegorizada o metaforizada. En este caso, dicho procedimiento se advierte desde el mismo título.

La historia, escrita en primera persona, presenta a un hombre perseguido, que se ha refugiado en una habitación de la cual el único modo de escapar es aprender a tocar la flauta para incorporarse a una "bandita" 
itinerante que recorre la ciudad de Buenos Aires. El enemigo del que hay que huir es el Falcon verde, auto empleado por las fuerzas represoras durante la dictadura cívico-militar que gobernó la Argentina entre 1976 y 1983: "unos automóviles verdes que llamaban Falcon [...] estos halcones husmeaban por toda la ciudad en mi busca" $(1989,155)$.

El exilio es el único modo de salvar la vida; en consecuencia, se presenta el momento en el que el protagonista sólo puede escapar de su tierra hacia cualquier lugar, como la última esperanza de supervivencia. Pero él no es el único perseguido: la casa donde habita está poblada por personas que intentan escapar del mismo modo, aprendiendo a tocar distintos instrumentos musicales.

Lo particular de este cuento es que el único recurso para escapar es lo musical. La "bandita" $(1989,155)$ es calificada de "milagrosa" $(1989,155)$ ya que su sola presencia impide el accionar de los represores. Esta calificación remite a dos ámbitos de significación de fuerte presencia en la narrativa moyaniana: la música y lo trascendente, entendido esto último como una perspectiva que supera la inmanencia para incorporar fenómenos no explicables desde una concepción puramente experiencial.

Si bien no hay una identificación concreta de la bandita, el director es un "rubio grandote" (¿un norteamericano?) $(1989,173)$ y se la presenta viajando en un vehículo que porta el letrero "Salva tu alma" (1989, 156); todo conduce a asimilarla al Ejército de Salvación, organización cristiana surgida en Estados Unidos cuyas Bandas de Bronces se convirtieron, a lo largo del tiempo, en referente inmediatamente reconocible para salvacionistas y no salvacionistas.

Lo más significativo de esta agrupación consiste en que su simple presencia permite suspender la amenaza de los represores: "Una bandita de música, precaria y de consistencia casi milagrosa, era lo único en Buenos Aires capaz de oponerse sin riesgos a la naturaleza asesina de unos automóviles que llamaban Falcon" $(1989,155)$. Esto sucede solo mientras los 
músicos están tocando; durante ese tiempo cada uno de los intérpretes posee inmunidad - de allí la intención del protagonista de incorporarse a la agrupación-.

Se manifiesta cómo la música constituye una amenaza para los perseguidores, en cuanto no se ajusta a la realidad impuesta por el poder. La potencialidad del arte permite escapar de las restricciones e instituir nuevos espacios alejados de todo control. La música crea un espacio particular, espacio de libertad para todos los que entran en él. Precisamente en el momento culminante del relato, el director prorroga la actuación para lograr salvar al protagonista.

Resulta importante también el espacio donde se produce la salvación: una plaza en la ciudad. La plaza como lugar de esparcimiento se presenta como una suerte de isla de normalidad, donde, gracias a la presencia de la banda musical, se recupera la ilusión de la vida sin persecuciones. El recuerdo de la plaza de la infancia se reitera en el recuerdo del protagonista, superponiéndose a la plaza real, hacia donde debe dirigirse. Se trata de una plaza donde también había una banda de música, cuya actuación estaba rodeada de un aura de inocencia y felicidad. Estaba formada -entre otrospor un "policía bueno" $(1989,157)$, se trataba de una "bandita de milagros semanales y caseros" (1989,163).

Diversas propiedades de lo musical lo vuelven peligroso para los poderosos: la inasibilidad, la labilidad que adquiere a partir de su composición esencial, en fin, su posibilidad de crear líneas de fuga difíciles de restringir. Se explicaría de este modo la importancia que adquiere la música en una sociedad donde el poder aparece con una capacidad casi omnímoda de control y represión.

Es significativa la representación de los perseguidores: automóviles modelo Falcon de color verde oliva, descritos con toda su carga de terror; equiparados con halcones, no solo por la similitud nominal sino por el carácter de la especie: los halcones son aves de rapiña, es decir, dedicadas 
a arrebatar con violencia ${ }^{2}$, en este caso, a personas. Por esto mismo, los autos se presentan animalizados, nunca se alude a sus conductores sino a su conducta, propia de una fiera al acecho: "El Verde, al parecer, gozaba con la cacería." $(1989,170)$. A la vez, los instrumentos musicales son considerados armas para las autoridades, ya que posibilitan la huida de los perseguidos.

La presencia de lo musical en el texto se funda en una cualidad ética de la música, casi indiscernible de la propia condición humana. Manuel Valls incorpora la dimensión musical a la condición humana y afirma: "La dimensión musical me hace «alguien»y me descubre, me pone en evidencia." $(1988,101)$.

La elección de la salvación (es decir, de la vida) ante el avasallamiento de la violencia y la muerte, implica la elección del discurso de la música - íntimamente relacionado con lo vital - como un modo de resistencia al Poder instituido. Este pensamiento es explicitado por Daniel Moyano, cuando escribe: "El arte en general es un discurso contra el poder. El poder, en general, es un discurso contra las personas" (Apud Gil Amate, 1993, 152).

"El halcón verde y la flauta maravillosa" es un relato donde se manifiesta la madurez creativa del escritor, que conjuga en un solo texto temas como el autoritarismo, la muerte, la infancia y la música. El mismo título remite a los cuentos infantiles (este recurso ya había sido utilizado por Moyano en su primera novela, Una luz muy lejana), de modo que el contrapunto entre la luminosidad de la infancia y la oscuridad del presente destaca la crueldad de los asesinos.

De este modo, el poder omnímodo de la dictadura aparece denunciado y combatido en un texto de elaboración impecable. 


\section{N. MARÍA VIOLÍN}

En este relato, publicado en la revista Crisis, en 1988, el protagonista es Manuel, un "suramericano" (1999, 33) exiliado en Madrid. Al igual que en el cuento anterior, tampoco se explicitan aquí las razones de esta situación, que se infiere también son de orden vagamente político ("hasta que aclare allá en el Cono Sur", 1999, 34).

Se trata de una historia de amor entre un hombre y una mujer cuyo único modo de comunicación es el musical: él toca la quena y ella, la flauta dulce. Ambos provienen de países muy alejados (Cono Sur, posiblemente la región andina/ algún país nórdico), y solo se acercan desde las ventanas enfrentadas. Este amor viene a rescatar a Manuel del dolor y la soledad del destierro, y lo devuelve a una dimensión sensible de la vida. Música y deseo físico se confunden y entrelazan.

Adquieren gran importancia las referencias a lo musical, dado que se convierte en el único código compartido por los personajes. La imposibilidad de comunicación lingüística remite a la búsqueda de medios alternativos: el juego de luces no tiene resultados positivos, en tanto la música de la quena obtiene la respuesta de la flauta dulce. A este código le siguen el gestual, el visual-fotográfico, la ropa, entre otros menos relevantes.

Encontrarse físicamente se transforma en una búsqueda desesperada entre calles y portales en un Madrid convertido en un laberinto. Ante la imposibilidad del encuentro callejero, Manuel opta por cruzar sobre la soga del tendedero, sin temor a la posible caída (mucho más endeble que el tablón de Cortázar, también mencionado en el texto).

Como en ninguna otra obra, en este relato Moyano establece fuertes lazos entre música y erotismo, de tal modo lo musical permite un acercamiento sensualmente más tangible y personalizado que el meramente lingüístico. El latido del corazón de Manuel es una percusión; así describe Roland Barthes esta capacidad que la música presenta, el latir: 
Lo que hay que hacer es conseguir que algo lata en el interior del cuerpo, contra las sienes, en el sexo, en el vientre, contra la piel interior, incluso en todo el complejo sensual- emotivo que llamamos, por metonimia y, a la vez, antífrasis, el “corazón” (1992,295).

En el relato se asevera que "los cuerpos han sido pensados para la música, son instrumentos vivos” (1999, 38). Finalmente, la música es también el producto de los cuerpos haciendo el amor, cuerpos que son instrumentos musicales (Manuel Arco, María Violín). La relación amorosa está entonces posibilitada por la música, y la genera a su vez, en un novedoso correlato amor/música.

La presencia de lo musical se plantea desde el mismo título - tal como sucede en los textos ya estudiados -. En "María Violín” está presente también en uno de los epígrafes, donde se cita a Pitágoras. Esta cita puede leerse como una explicación del término "monocordio" que se emplea en el texto para aludir a una prenda íntima femenina; pero también como una clave de lectura que remite a concepciones que Moyano conocía y compartía. En diversas entrevistas hace alusión al astrónomo Kepler (en un reportaje manifiesta su interés por este científico, de quien afirma: "El decía, por ejemplo, que la tierra al desplazarse producía un sonido, una música en el espacio. Pero que esa música no se la podía oír con los oídos, sino con el intelecto" (Gilio, 1985, 44) y su búsqueda de la armonía cósmica.

Según Carl Sagan, "la palabra armonía tenía para Kepler muchos significados: el orden y la belleza del movimiento planetario, la existencia de

3 "Pitágoras descubrió las leyes matemáticas de los intervalos musicales valiéndose de un aparato de su invención que llamó monocordio. Este consistía en una caja de resonancia sobre la que puso una cuerda tensa apoyada por sus extremos en dos caballetes. Dividiéndola, mediante otro caballete, en dos pares exactamente iguales, comprobó que el sonido producido por cada uno de los segmentos era la octava del sonido que daba la cuerda dejándola vibrar en libertad. [De las clases del conservatorio]" (1999, 33). 
leyes matemáticas explicativas de ese movimiento - una idea que proviene de Pitágoras- e incluso la armonía en sentido musical, la "armonía de las esferas" $(1992,62)$. En el relato, el encuentro entre María y Manuel es también una forma de encontrar la armonía entre los seres.

Pitágoras no aparece solo en un epígrafe del cuento, sino que se reitera en su desarrollo. Para el filósofo griego, Cosmos es igual a Orden, y como tal establece relaciones entre todos y cada uno de los seres del universo: “arriba y abajo, las almas y las cosas se corresponden”(Ghyka, 1978, 90). Más que una correspondencia superficial, se postula la presencia de un mismo principio ordenador (vital) tanto en las menores expresiones como en el movimiento de los astros. De tal manera, existiría una armonía de los elementos, un principio musical de organización cósmica, "la armonía de las esferas", que también rige para las relaciones entre los seres humanos.

Otra particularidad de la obra moyaniana en su etapa de madurez, es la fuerte presencia de la intertextualidad, tanto con letras de canciones ("en la tarde gris de tango", "senza mamma e senza amore", 1999, 35) como con textos literarios. En el relato, aparecen citas de César Vallejo ("me moriré en París con aguacero", 34 y "qué hará a esta hora mi andina y dulce Rita de junco y Capuli", 1999, 35), Cesare Pavese ("verrà la morte a avrà i tuoi occhi", 1999, 37) y el romance tradicional español "El enamorado y la muerte". Este poema se enlaza con la estructura misma del relato ya que la música producida por los enamorados es descrita por el narrador con palabras que siguen el hilo del romance tradicional español: "acorde perfecto equiparable a decir amor mío, para que subas arriba, la dama fría muy más que la muerte se va, y si el hilo no alcanzare mis trenzas añadiría" $(1999,38)$.

En este texto, la música aparece en diversos niveles; tanto en lo discursivo como en lo temático. El final alcanza un vuelo lírico que abandona el realismo inicial para incluir la posibilidad de lo maravilloso que aporta el amor unido a lo musical. 


\section{$\vee$.}

Si bien la crítica reitera la importancia de la música en la obra de Daniel Moyano, es difícil encontrar un estudio donde se profundice en el tema. A partir de lecturas reiteradas de la narrativa del autor argentino, hemos desarrollado una perspectiva de lectura que ahonda en la presencia de la música y su confluencia con la literatura en los textos.

En el presente artículo, se han seleccionado tres cuentos que recorren la trayectoria escrituraria de Moyano, donde la presencia de la música tiene diversas manifestaciones.

En "Cantata para los hijos de Gracimiano" comienza a asomar lo musical como modelo de la escritura: la sucesión de voces diversas, todas de igual relevancia, que van desarrollando diferentes perspectivas sobre los hechos narrados, remite a la forma de la cantata.

Sin embargo, la presencia de la música no sirve para modificar en nada la situación de despojamiento de una familia destruida por el hambre y la miseria, apenas alivia en algo el momento de la separación. El final del relato no deja lugar a la esperanza, ni el menor resquicio de una posibilidad de reparación a un mal imposible de remediar.

Se marca una fuerte diferencia con los otros dos relatos; lo musical atraviesa la narración tanto en "El halcón verde y la flauta maravillosa" como en "María Violín”. En el primero de ellos, la música se convierte en la única posibilidad de supervivencia (espiritual y física) ante el mal; mientras que su capacidad para transmitir sentimientos se manifiesta especialmente en "María Violín", donde lo erótico y lo musical se fusionan en la unión deseada de los amantes.

Aparecen en estos textos propiedades de la música que posibilitan la salvación en el plano político-social, en tanto preserva al individuo ante los ataques del poder. A diferencia de Gracimiano y Gracimiana, el flautista improvisado logra escapar de la muerte con solo una nota. Por otro lado, 
en "María Violín", la música se convierte en el puente que permite la concreción del amor: otro modo de salvación del ser humano, más allá de todas las diferencias y distancias.

Estos relatos se alejan del realismo en un devenir hacia lo trascendente; a la manera marechaliana, los protagonistas pueden salir de sus respectivos laberintos con un salto hacia arriba; hacia las regiones donde la armonía nacida de lo musical rige el funcionamiento del universo mismo.

La elección de la música como resultado de una opción ética, más que política, se evidencia a partir de las funciones que va adquiriendo en las obras: desde lo simplemente argumental hasta lo profundamente hermenéutico. La música se instituye de tal modo como el otro mundo: el de la justicia, el de la creación, el de la vida. Los procedimientos mediante los cuales este otro se enreda con lo literario -hasta hacer tambalear los límites impuestos por la propia especificidad de su discurso-, determinan el carácter único de la narrativa de Daniel Moyano, y explican el por qué de su particularidad en el dilatado campo de la literatura argentina.

Lo musical se postula como opción para una escritura que, al autocuestionarse, va extendiendo sus fronteras mediante la incorporación de códigos alternativos. Un recurso es la problematización del código utilizado. Las palabras se desmenuzan y analizan no sólo desde el punto de vista morfológico sino también en sus aspectos fónico y semántico. No nos hemos limitado a un concepto restringido de discurso, pues la función modelizadora o paradigmática de lo musical abarca diversos niveles compositivos de los textos, de tal modo están relacionadas en su misma concepción las series musical y literaria.

En la escritura moyaniana, también es posible señalar la presencia de procedimientos propios del discurso musical (tema con variaciones, cadencia, modulaciones, leitmotivs), así como la construcción de estructuras narrativas modelizadas por la música.

Desde dicha interdiscursividad literatura-música, hasta la institución de 
esta última como un contradiscurso, es decir, un espacio de resistencia contra los poderes instituidos y una instancia ética de preservación de los valores individuales y comunitarios; lo musical finalmente adquiere una fuerza que permite la religación entre el hombre y el todo.

\section{REFERENCIAS BIBLIOGRÁFICAS}

Barthes, Roland. Lo obvio y lo obtuso. Barcelona: Paidós, 1992.

Casarin, Marcelo. Daniel Moyano. El enredo del lenguaje en el relato. Una poética de la ficción. Córdoba: Ediciones del Boulevard, 2002.

Casarin, Marcelo (coord.). Tres golpes de timbal/Daniel Moyano; edición crítica. Córdoba: Alción Editora, 2012.

Corona Martínez, Cecilia. Literatura y música. Confluencias en la obra de Daniel Moyano. Córdoba: Universitas, 2005.

Gil Amate, Virginia. Daniel Moyano: la búsqueda de una explicación. Universidad de Oviedo: Departamento de Filología Española, 1993.

Gilio, María Esther. "Daniel Moyano: la música que brota de la tierra". In: Crisis, n 22, 1975, 40-47.

Ghyka, Matila. El número de oro, V.II, Barcelona: Poseidón, 1978.

Lévi Strauss, Claude. Mitológicas. Lo crudo y lo cocido. México: FCE, 1968.

Moyano, Daniel. "Cantata para los hijos de Gracimiano". In: AAVV. El cuento argentino, 1959-1970. Buenos Aires: Centro Editor de América Latina, 1981,71-79.

" "El halcón verde y la flauta maravilloso", In: El trino del diablo y otras modulaciones. Buenos Aires: Grupo Ed. Zeta, 1989,153-176. 

1999, 33-47.

RAE (Real Academia Española). Diccionario de la Lengua Española. Madrid: Espasa Calpe, 2000.

Sagan, Carl. Cosmos. Barcelona: Planeta, 1992.

Schweizer, Rodolfo. Daniel Moyano (Las vías literarias de la intrahistoria). Córdoba: Alción, 1996.

Stephan, Rudolf. Música. Buenos Aires: Fabril Editora, 1964.

Valls, Manuel. La música en el abrazo de Eros. Barcelona: Tusquets, 1982. 